\title{
Estratégia da Atenção Psicossocial e participação da família no cuidado em saúde mental
}

I ${ }^{1}$ Magda Dimenstein, ${ }^{2}$ André Luis Sales, ${ }^{3}$ Ellen Galvão,

${ }^{4}$ Ana Kalliny Severo I

Resumo: Este trabalho tem como objetivo discutir como familiares de portadores de transtornos mentais têm experienciado as mudanças nas políticas da área, o que pensam sobre as novas demandas de participação e como as mesmas têm impactado na sua relação cotidiana com os serviços de saúde mental e nas práticas de cuidado junto a seus familiares. A pesquisa foi realizada no ambulatório de saúde mental de Natal entre novembro de 2008 e fevereiro de 2009, como parte de um trabalho de mestrado que objetivava analisar processos de cronificação em curso nesse serviço. Foram realizadas 12 entrevistas, sendo sete com familiares e cinco com usuários. Os resultados evidenciam as inúmeras dificuldades dos familiares junto às novas propostas de cuidados em saúde mental, que interferem diretamente na perspectiva de corresponsabilização posta pela Estratégia da Atenção Psicossocial. Acreditamos que tal construção entre técnicos e familiares deve vir acompanhada de ações de suporte às famílias, de mudanças nos modos de trabalho e gestão, bem como de avanços em relação às políticas de inclusão social e reabilitação psicossocial, de fortalecimento de mecanismos de controle social, de estímulo ao empoderamento dos usuários e familiares no sentido de fazer avançar o processo de desinstitucionalização em saúde mental.

> Palavras-chave: reforma psiquiátrica; saúde mental; reabilitação psicossocial, co-responsabilidade, família.

\author{
1 Psicóloga, Doutora em Saúde \\ Mental pelo Instituto de \\ Psiquiatria da UFRJ, professora \\ da UFRN. Pesquisadora do \\ CNPq. Endereço eletrônico: \\ magda@ufrnet.br \\ 2 Psicólogo pela UFRN \\ Bolsista de Apoio Técnico pelo \\ CNPq. Endereço eletrônico: \\ andreluislfs@gmail.com \\ ${ }^{3}$ Graduanda em Psicologia na \\ UFRN. Bolsista de IC/CNPq. \\ Endereço eletrônico: ellen_ \\ ufrn_galvao@yahoo.com.br \\ ${ }^{4}$ Psicóloga, Mestre em \\ Psicologia pela UFRN e \\ Professora do Curso de \\ Psicologia da Universidade \\ Potiguar. Endereço eletrônico: \\ akssevero@gmail.com
}

Recebido em: 27/10/2009. Aprovado em: 30/04/2010. 
A Reforma Psiquiátrica em curso no país, com o envolvimento de diversos atores sociais, tem por objetivo substituir o modelo hospitalar, segregador, excludente e tutelar que por muito tempo teve, e ainda tem, a primazia nos cuidados no campo dos transtornos mentais (AMARANTE, 1995). Os avanços dessas discussões culminaram na criação de uma série de políticas públicas que têm como objetivo a redução progressiva dos leitos em hospitais psiquiátricos, pari passu a construção de uma rede de serviços substitutivos capazes de prestar assistência mais qualificada à população que outrora dependia exclusivamente do hospital. Os principais recursos que hoje estão implementados como alternativas terapêuticas aos manicômios são os Centros de Atenção Psicossocial (CAPS), Serviços de Residência Terapêutica (SRTs), os leitos psiquiátricos em hospitais gerais, o Programa de Volta para Casa e os atendimentos prestados pelas equipes de saúde da Atenção Básica (BRASIL, 2004).

Esses dispositivos visam a estabelecer cuidados em saúde mental dentro de um modelo de atendimento integral que preza a permanência dos indivíduos na sua comunidade, favorecendo a formação de vínculos estáveis e garantindo seus direitos de cidadãos. $\mathrm{O}$ intuito deste movimento é mudar o paradigma manicomial de atenção ainda vigente no país e, em seu lugar, consolidar o paradigma psicossocial. Isto implica mudanças de diversas ordens, desde realocar as verbas do setor - que se concentravam historicamente nos dispositivos hospitalares - para os serviços substitutivos, até os modos de trabalho desenvolvidos pelas equipes dentro do cotidiano dos serviços (CONSOLI; HIRDES; COSTA, 2009; HIRDES, 2009). Um dos pontos críticos das transformações em curso diz respeito à participação dos familiares no cuidado e reabilitação do portador de transtorno mental (WAIDMAN; ELSENS, 2005). A proposta deste trabalho é pensar as implicações da adoção do paradigma psicossocial (COSTA-ROSA, 2003), enquanto política que direciona as ações em saúde mental, em relação ao lugar da família nesse processo.

Tomaremos o Paradigma Psicossocial e o Paradigma Psiquiátrico Hospitalocêntrico Medicalizador como modelos de referência no campo da saúde mental. Paradigma é entendido aqui como uma "agregação dos diferentes vetores das pulsações tanto em termos de ação instituinte quanto de resistências do instituído no campo da Saúde Mental" (COSTA-ROSA, 2006, apud YASUI; COSTA-ROSA, 2008, p. 28). 
O Paradigma Psiquiátrico Hospitalocêntrico Medicalizador fundamenta-

se no princípio doença-cura, em uma organização de serviços estratificada e hierarquizada, com a busca de remissão de sintomas. Já o Paradigma Psicossocial compreende o processo de saúde-doença como "processos sociais complexos e que demandam uma abordagem interdisciplinar" (YASUI; COSTA-ROSA, 2008, p. 29). Está inspirado nos movimentos reformistas que visam a colocar a existência de sofrimento e as condições materiais de produção deste como foco do tratamento. Preza práticas sociais que possibilitem a inclusão de indivíduos que historicamente são alvo de forte exclusão social, estigma e preconceito. Em outras palavras, o paradigma psicossocial preconiza um trabalho na perspectiva da desinstitucionalização, não focada na cura da doença, na readaptação dos indivíduos, na normalização dos sujeitos, mas na existência de sofrimento humano como objeto real de uma intervenção (ROTELLI; LEONARDIS; MAURI, 2001).

Na perspectiva acima, a família representa um problema. O paciente deve ser isolado na medida em que esta é tomada como fator determinante no processo de enlouquecimento e adoecimento (BORBA; SCHWARTZ; KANTORSKI, 2008; COLVERO; IDE; ROLIM, 2004). A experiência da loucura é tomada como doença mental justificando e fundamentando tratamentos que têm por base a medicação, o isolamento, a exclusão e adoção de uma perspectiva moralizante. O foco do tratamento é a doença em si, tomada como decorrente de uma patologia orgânica. Portanto, a família é mais um elemento patógeno que precisa ser eliminado. As mudanças que vêm se processando no campo da saúde mental indicam uma perspectiva diferente em relação ao lugar da família, que vem sendo chamada a atuar como corresponsável pelo cuidado e reinserção social de seus membros (BIELEMANN et al., 2009; CAMATTA; SCHNEIDER, 2009; BORBA; SCHWARTZ; KANTORSKI, 2008; COLVERO; IDE; ROLIM, 2004).

Sendo assim, nosso intuito é discutir como familiares de portadores de transtornos mentais têm experienciado essas mudanças nas políticas da área, o que pensam sobre as novas demandas de participação e como as mesmas têm impactado sua relação cotidiana com os serviços de saúde mental e nas práticas de cuidado junto a seus familiares, de modo a contribuir para uma melhor compreensão do lugar desses familiares dentro desses arranjos de cuidado. 


\section{O Paradigma Psicossocial e as demandas para família e/ou cuidadores}

O uso que fazemos aqui do termo "paradigma" diz respeito também a uma aproximação da forma como ele é usado por Kunh (2006). Trata-se de um conjunto de conceitos e arranjos que são tomados como válidos para que seja possível, a partir dele, construir conhecimento. Um paradigma forneceria os fundamentos sobre os quais uma dada comunidade científica desenvolve suas atividades. Ele seria algo parecido com um "mapa" a ser usado pelos cientistas na exploração da natureza. Este guia de observação, este referencial sobre o qual as práticas se erigem é algo que modela a produção do conhecimento. É esta aproximação que nos interessa, na medida em que estão em voga hoje diversos princípios orientadores para o trabalho em saúde mental, que estão exercendo uma função paradigmática. Tais princípios são diferentes dos outrora vigentes e, sendo assim, seus efeitos se materializam de outros modos no cotidiano dos indivíduos que são alvo desse cuidado (CAMATTA; SCHNEIDER, 2009; SILVA; SADIGURSKY, 2008; CAMPOS; SOARES, 2005).

Como dito anteriormente, a principal característica do modelo tradicional hospitalocêntrico e manicomial é estar ancorado no princípio da doença-cura, atendo-se, preferencialmente, ao aspecto orgânico do sofrimento - fator do qual decorre a ênfase em terapêuticas medicamentosas. Sua base tende a ser atualizada cotidianamente pela via de atendimentos centrados em sintomatologias, classificações nosológicas e pela prática da reclusão - fruto da aliança histórica entre loucura, pobreza e exclusão (FOUCAULT, 2004). Há no horizonte uma perspectiva de cura e de normatização/normalização das condutas (COSTAROSA, 2003). O atendimento ao paciente se dá de forma segmentarizada, dentro de uma perspectiva de especialidades múltiplas, mas atuando em separado. Não estão previstos atendimentos conjuntos, nem muito menos trocas de informações e planejamento das ações dos diferentes profissionais. $\mathrm{O}$ instrumento a partir do qual eles se comunicam é o prontuário - muitas vezes preenchido de modo burocrático e com poucas informações sobre a vida do paciente.

No que diz respeito ao Paradigma de Atenção Psicossocial, situado na interface entre Saúde Mental e Saúde Coletiva, parte-se do entendimento de que saúde-doença é resultante de processos sociais complexos, demanda uma abordagem interdisciplinar e intersetorial e a construção de uma diversidade 
de dispositivos territorializados de atenção e de cuidado. Nele, o sujeito em sofrimento é o alvo da intervenção. Seu entorno social, seu contexto de vida, trabalho e relações sociais são tomados como fatores importantes no processo de atenção. A medicação passa a ser encarada como mais um recurso - e não como o único e principal artefato ao redor dos qual todos os demais orbitam. Para além do tratamento medicamentoso, são investidas novas formas de atenção e cuidado que prezam pela interdisciplinaridade, pelo intercâmbio, pela mistura, pela mixagem de diferentes saberes, de modo a produzir uma intervenção que considere a complexidade dos problemas relacionados à saúde mental, visando, especialmente, à construção de redes sociais de suporte nas quais o indivíduo possa se inserir (YASUI; COSTA-ROSA, 2008).

A aposta é no aumento do poder de contratualidade, de modo que os portadores de transtornos mentais possam construir laços, participar da vida cotidiana, circular nos mais diversos espaços sociais. A perspectiva de reclusão presente no paradigma manicomial é abolida na medida em que a vida cotidiana e os laços sociais são valorizados e retomados, caracterizando a Estratégia da Atenção Psicossocial como eminentemente territorial. Como foi dito acima, o foco da atenção e do cuidado não é a doença, nem muito menos seus sintomas na perspectiva biológica e normalizante, mas a existência de sofrimento e as condiçōes materiais de produção de vida e, consequentemente, de produção de saúde e adoecimento. De acordo com a perspectiva de reabilitação psicossocial proposta por Saraceno (1996), um foco importante a ser trabalhado é a questão do poder de contratualidade. Este seria a capacidade do indivíduo de realizar suas trocas afetivas e materiais dentro do meio social. Os manicômios são espaços onde o nível das trocas é eminentemente baixo, devido, dentre outros fatores, ao caráter assimétrico das relações que lá se estabelecem. Na perspectiva desse autor, aumentar o poder de troca e a circulação dos indivíduos dentro dos espaços da cidade onde estas trocas acontecem deve ser uma das preocupaçōes centrais dos movimentos reformadores.

Franco Basaglia, psiquiatra reformista italiano que influenciou fortemente o processo de reforma desencadeado no Brasil, já defendia em 1960 o fortalecimento dos vínculos existentes entre familiares e profissionais que atuam nos serviços. Entendia que essa articulação é a base de uma perspectiva de corresponsabilização do cuidado - vista como fundamental na proposta terapêutica defendida 
atualmente pelos reformadores no país. Basaglia também apontava como fundamental a transformação dos modos de relação com os indivíduos portadores de sofrimento mental. Nesse ponto, defendia o reordenamento das posições, papéis e mesmo das motivaçôes que se presentificam no ato de cuidar. Segundo ele, as ações de cunho mais terapêutico são aquelas que combatem a infantilização do doente, sua manutenção na condição de inválido, de incapaz, e que favorecem uma vida menos tutelada (BASAGLIA, 1991).

Muitos são os desafios nesse processo de transformação dos modos tradicionais de cuidado em saúde mental, passando pela formação dos profissionais, até os interesses políticos e econômicos da indústria farmacêutica, que vê na mudança de modelo uma potencial perda de mercado (YASUI; COSTA-ROSA, 2008). Entretanto, um dos pontos mais desafiantes na atualidade é a adesão da família a esses novos princípios, pois uma implicação direta dessa mudança paradigmática para familiares e cuidadores de portadores de transtornos mentais é a necessidade de corresponsabilização pelo cuidado. Os vínculos com os familiares que tendiam a ser enfraquecidos durante os longos períodos de internação (CAMATTA; SCHNEIDER, 2009; SILVA; SADIGURSKY, 2008; CAMPOS; SOARES, 2005) passam a ser prezados, cultivados e trabalhados dentro da perspectiva de atenção territorial (COSTA-ROSA, 2003).

Dimenstein e outros autores (2007) indicam que o investimento das políticas públicas na família não é recente. Desde o século XIX, o Estado tem direcionado seus esforços no sentido de ter a família como aliada e multiplicadora de seus princípios visando à produção de um ordenamento social. No campo da saúde pública, isso fica evidenciado especialmente em políticas sociais mais recentes, como o SUS, PACS, Sistema Único de Assistência Social (SUAS) etc. No entanto, essas alianças sempre estiveram pautadas em perspectivas etnocêntricas e normativas acerca dos modelos familiares, do seu funcionamento, da sua dinâmica social e psicológica, bem como dos modos como cuidam uns dos outros. Seus saberes e práticas foram desconsiderados, tornando-os meros consumidores de prescrições calcadas no modelo biomédico e coadjuvantes dos mais diversos especialistas.

Melman (2001) analisa que, historicamente, o aprisionamento do louco em hospitais psiquiátricos foi justificado por teorias médicas que afirmavam a necessidade do seu isolamento da família, ora explicando que a família precisava ser protegida da loucura, prevenindo-a das influências negativas 
como indisciplina e desordem moral, ora porque a família foi tomada como propiciadora de doença mental. A família era encarada como um fator adoecedor do qual o indivíduo adoecido deveria se proteger e se afastar para que a cura fosse alcançada. Além disso, a exclusão familiar do tratamento devia-se ao fato de ser vergonhoso socialmente ter um membro em sofrimento mental dentro de casa. Essas concepções ainda circulam e estão presentes em nosso imaginário cultural, tornando ainda mais problemática a adesão dos familiares ao tratamento. Contudo, as relaçóes entre a família e o portador de transtorno mental foram se modificando a partir das produções científicas e culturais em torno da loucura. A antipsiquiatria e as propostas reformistas da Psiquiatria Democrática Italiana, a partir das décadas de 1960 e 1970, detiveram atenção especial à forma como a família vinha sendo escamoteada pela psiquiatria. Além de realizarem uma crítica ao modo como o saber médico-psiquiátrico contribuía para a manutenção da situação de abandono dos indivíduos dentro dos manicômios, convocaram as famílias a se inserirem no tratamento, na medida em que passaram a questionar a base psiquiátrica de compreensão da loucura e da própria família.

Observa-se, de um modo geral na literatura do campo, que as mudanças nas formas de tratamento oferecidas aos pacientes portadores de transtorno mental produzem nas famílias o sentimento de desamparo, descuido, incapacidade de prestar um cuidado adequado e despreparo para enfrentar situações de crise e o manejo do cotidiano. Além disso, também enfrentam dificuldades financeiras de atender às necessidades de novos medicamentos e atividades extrahospitalares, bem como fragilidade emocional provocada pelo adoecimento de um dos membros da família (JORGE et al., 2008; NAVARINI; HIRDES, 2008; BORBA; SCHRANK; KANTORSKI, 2008; DIMENSTEIN et al.; 2007; ROMAGNOLI, 2006; CAMPOS; SOARES, 2005). Alguns autores, discorrendo sobre as insatisfações e dificuldades enfrentadas por esses familiares, apontam os mesmos precisam manejar constantemente

a dificuldade para lidarem com as situações de crise vividas, com os conflitos familiares emergentes, com a culpa, com o pessimismo por não conseguir ver uma saída aos problemas enfrentados, pelo isolamento social a que ficam sujeitos, pelas dificuldades materiais da vida cotidiana, pelas complexidades do relacionamento com o doente mental, sua expectativa frustrada de cura, bem como pelo desconhecimento da doença propriamente dita, para assinalarmos, algumas dentre tantas outras insatisfações (COLVERO; IDE; ROLIM, 2004, p. 198). 
Dessa forma, tais estudos indicam a necessidade de dar mais suporte às famílias e/ou cuidadores, de modo a ampará-los nesse contexto de mudanças, seja na vida familiar, seja em termos da responsabilização, pelo cuidado e da relação com equipe e serviços de atenção. O presente trabalho é fruto de uma pesquisa que teve como um de seus eixos de investigação as implicações da mudança em termos de atenção para as famílias de usuários de serviços de saúde mental. Tem ainda por objetivo traçar alguns caminhos na perspectiva de corresponsabilização família/técnicos.

\section{Apresentação do campo e procedimentos metodológicos}

A pesquisa ${ }^{1}$ foi realizada no ambulatório de saúde mental de Natal, entre novembro de 2008 e fevereiro de 2009, como parte de um trabalho de mestrado ${ }^{2}$ que objetivava analisar processos de cronificação em curso nesse serviço. $\mathrm{O}$ Ambulatório de Saúde Mental está em funcionamento desde 2001, apenas no período da manhã, e disponibiliza atendimento em grupo, consultas, oficinas terapêuticas, bem como passeios, sessôes de cinema e outras atividades que trabalhem na perspectiva da reinserção social, ainda que com menor frequência. A equipe do serviço é composta por dez técnicos, sendo três psicólogas, uma assistente social, uma filósofa, uma arte-educadora, uma auxiliar de enfermagem e três psiquiatras. Os procedimentos realizados foram análise dos prontuários e livros de registros do serviço de saúde objetivando traçar um perfil da clientela, rodas de conversa (AFONSO; ABADE, 2008) com os técnicos, observação do cotidiano do serviço e entrevista semiestruturada com alguns usuários e familiares definidos a partir desse perfil. Priorizamos os usuários que já pudessem estar de alta do serviço e os familiares correspondentes.

A partir das informações levantadas junto aos registros do serviço - tipo de atendimento prestado pelo serviço ao indivíduo, tempo de inserção no serviço, grau de instrução, contexto familiar onde está inserido, renda mensal e distrito sanitário onde reside -, realizamos quatro rodas de conversa com parte da equipe técnica do serviço (com exceção dos psiquiatras), abordando principalmente o tema da cronificação dos usuários dentro dos serviços substitutivos. Este tema disparou outras questôes, como a falta de assistência da rede básica em saúde mental, as atividades realizadas no serviço, a demanda atendida, a falta de articulação do serviço com a comunidade, a participação das famílias dos usuários no tratamento e o tema da alta do serviço. 
Nessas rodas de conversas junto à equipe, selecionamos dez usuários que já poderiam estar de alta para integrar a segunda parte da pesquisa. A partir dessa escolha, contatamos os usuários e fizemos uma visita domiciliar com a finalidade de entrevistar os cuidadores. A entrevista foi guiada por um roteiro semiestruturado que abordava os seguintes aspectos: necessidades de cuidado do usuário; dificuldades encontradas pelos familiares para atendê-las; participação do ambulatório na oferta de cuidados; impacto da saída do usuário do serviço e os recursos comunitários e de assistência à saúde de que os participantes dispõem. Dos dez usuários selecionados, encontramos apenas sete com os quais se realizou as entrevistas - os endereços dos outros três não foram localizados. Ainda que não tivesse sido o planejado, optamos por realizar entrevistas com os usuários que estavam presentes no momento das visitas. Ao todo foram realizadas 12 entrevistas, sendo sete com familiares e cinco com usuários. O registro das atividades de pesquisa foi feito a partir de diários de campo e de gravação previamente autorizada pelos participantes - das entrevistas.

\section{Resultados e análise}

\section{Sobre os usuários e seus familiares}

Os usuários entrevistados nesta etapa específica da pesquisa fazem parte dos 214 cadastrados no ambulatório no momento em que se realizou a investigação. Apesar da inexistência de muitas informações nos prontuários, observamos que o perfil predominante no serviço é de usuários do sexo feminino, solteiros e natural de Natal-RN. A faixa etária da maioria está entre 41 e 50 anos, e o grau de instrução é bastante diversificado, sendo que o nível fundamental incompleto se destaca. Quanto à renda, a grande maioria não possui salário ou benefícios sociais. Muitos usuários residem com familiares e/ou cônjuge e os domicílios localizam-se predominantemente nos distritos sanitários leste e oeste da cidade de Natal. Muitos apresentam o diagnóstico de esquizofrenia, têm histórico de internação psiquiátrica, são oriundos de outros serviços substitutivos como CAPS e Hospital-Dia e fazem uso do ambulatório, especialmente em função das consultas psiquiátricas mensais.

Dos 214 usuários, 42\% utilizam o serviço para consultas psiquiátricas, participação no grupo Bom Dia-espaço de acolhimento onde os usuários conversam sobre diferentes temas escolhidos por eles e os técnicos fornecem avisos acerca das atividades e dinâmica do serviço e oficinas. $\mathrm{O}$ restante vai ao ambulatório apenas 
para consultas psiquiátricas e participação no grupo. Dos sete usuários encontrados que tinham indicação de alta pela equipe, apenas cinco concordaram em participar da pesquisa. Estavam na faixa etária de 50 a 60 anos e frequentavam o ambulatório há mais de seis anos, indo às consultas psiquiátricas e participando de atividades como as oficinas de arte e do grupo Bom Dia. Apenas uma mora sozinha, porém perto da mãe, e os outros usuários residem com o que categorizamos enquanto família mais ampla, que engloba pais, sobrinhos, cunhados, irmãos, tios(as), vizinhos e outros. Quanto ao histórico de internação psiquiátrica desses usuários, apenas dois usuários foram internados. Quanto à passagem por outros serviços substitutivos, apenas um usuário já havia passado por outros serviços e os outros não possuíam dados nos prontuários nesse sentido.

Em relação aos familiares entrevistados, seis eram mulheres e apenas um homem, com idades variando, sobretudo, entre 30 e 50 anos. As mulheres entrevistadas variavam bastante em seu grau de parentesco com o usuário, existindo irmã, cunhada, duas filhas, mãe, esposa. O homem entrevistado era filho da usuária. Pelos dados disponíveis, observamos que a maior parte dos familiares não tem participação ativa nas atividades propostas pelo ambulatório. Eventualmente acompanham o usuário, pelo fato de considerarem que eles têm autonomia para se deslocarem sozinhos. Quanto à situação de moradia, o número de pessoas da família residentes no mesmo domićlio varia, predominando cinco pessoas por casa. Essas famílias residem no Distrito Sanitário Oeste do município de Natal, área carente da capital que apresenta graves indicadores sociais, a saber: maior índice de mortalidade infantil da cidade; maior índice de gravidez precoce e maior incidência de doenças sexualmente transmissíveis e Aids. Além disso, a Zona Oeste apresenta o maior índice de homicídios, além de um nível bastante alto de transgressóes cometidas pela população jovem. É uma área da cidade com pouca oferta de opções de lazer e cultura, bem como de dispositivos de apoio social e comunitário.

Ressaltamos que a ausência de muitos dados no serviço acerca desses usuários e seus familiares reflete a falta de um trabalho mais consistente pela Secretaria Municipal de Saúde do município, de estimular e organizar o uso das ferramentas institucionais tais como os prontuários, de maneira que sirvam, de fato, para orientar as equipes dos diferentes serviços por onde passa esse usuário, em termos do seu histórico de vida, incluindo questóes sanitárias, familiares e sociais. Além disso, a ausência de informações dificulta o trabalho das equipes, no sentido 
de pensar intervenções contextualizadas de acordo com os recursos pessoais, familiares e sociais disponíveis em seu entorno.

A seguir, apresentaremos os resultados encontrados a partir dos eixos que compuseram o roteiro de entrevista, a saber: necessidades de cuidado do usuário, dificuldades encontradas pelos familiares para atendê-las, participação do ambulatório na oferta de cuidados e os recursos comunitários e de assistência a saúde de que os participantes dispõem e utilizam.

Sobre as dificuldades enfrentadas pelos familiares, observamos que eles buscam estimular a autonomia dos usuários, instigando a saída de casa sem companhia, a realização das atividades cotidianas e o controle sobre sua própria medicação como forma de compartilhar responsabilidades. Em função disso, declararam que os usuários não necessitavam de nenhum cuidado especial, pois eles eram independentes para sair, resolver seus problemas, realizar atividades de casa. Entretanto, esses mesmos familiares, quando indagados sobre dificuldades enfrentadas para prestar o cuidado, relataram falta de tempo, falta de conhecimento específico sobre o transtorno mental, falta de habilidade e suporte para lidar com situação de crise e com as mudanças ocorridas na rotina familiar mediante a situação de adoecimento. Indicaram a necessidade de, em certos momentos, adotar uma postura de maior vigilância, queixando-se, então, de sobrecarga física e financeira, tendo em vista que esta é apenas mais umas das inúmeras funções que exercem em seus contextos familiares. Tais achados se juntam a uma diversidade de estudos que apontam para este acúmulo de função como algo que torna a questão do cuidado ao indivíduo em sofrimento mental crônico ainda mais complexa (NAVARINI; HIRDES, 2008).

A situação de não poder atender às demandas de cuidado tem gerado um desconforto para os familiares, provocando um sentimento de culpa muito forte. Notamos, assim, que o convite a uma maior participação familiar tem levado essas famílias a desejarem integrar-se mais aos projetos de cuidado dos usuários. Contudo, este imperativo de participação familiar, que implica a realização de uma série de atividades, inclusive fora do espaço doméstico, acaba contribuindo para a sobrecarga visivelmente sentida entre tais cuidadores, o que reforça a necessidade de serem também acolhidos pelas políticas da área (BORBA; SCHWARTZ; KANTORSKI, 2008; JORGE et al., 2008; NAVARIN; HIRDES, 2008; COLVERO; IDE; ROLIM, 2004). E isso foi claramente 
percebido na pesquisa: os familiares são convocados a participar, percebem sua importância no processo, mas não têm disponibilidade para isso. Por outro lado, os profissionais se queixam dessa ausência e do aumento de trabalho para a equipe que tal ausência provoca. Dessa situação derivou o reconhecimento, pela equipe, da necessidade de oferecer algum tipo de suporte para estas famílias, de modo que possam sustentar uma perspectiva de corresponsabilização pelo cuidado. Contudo, na rotina no ambulatório, existem poucos espaços e momentos onde este acolhimento e suporte ao familiar são discutidos como uma prática de cuidados básicos a ser incorporada e ofertada.

Já nas conversas com os usuários sobre suas necessidades de cuidado, evidenciouse que o ambulatório de saúde mental é utilizado como um espaço de lazer, socialização e diversão. Notamos que estes usuários não estão vinculados a outros serviços de saúde, nem a outros espaços sociais, mantendo-se no restrito circuito casa-serviço-casa. Isso indica que, além das demandas de acompanhamento e seguimento psiquiátrico, que poderiam continuar a ser atendidas no ambulatório, esses usuários necessitam circular em outras redes que possam dar suporte às suas diversas necessidades de saúde e socialização. Em função disso, a possibilidade de desvinculação do serviço ou de "alta" é incômoda, sendo vista como algo extremamente negativo ou mesmo como punição por mau comportamento.

Em outras palavras, encontramos um cenário onde o ambulatório ocupa lugar central no cotidiano dos usuários e familiares, suprindo precariamente necessidades de assistência, de suporte social e assessoramento às famílias. $\mathrm{O}$ fato de os usuários serem egressos de longos períodos de CAPS II e estarem em condição de maior estabilidade torna o ambulatório o ponto final de ancoragem de pessoas que poderiam seguramente estar vinculadas às equipes de saúde da família, às unidades de atenção básica, com retaguarda dos CAPS em caso de necessidade e/ou crise. Por outro lado, é uma segurança para as famílias que se sentem cotidianamente desamparadas e exigidas de participar de um processo do qual foram historicamente excluídas, conforme ressaltado anteriormente. A convocação de que se faça presente no tratamento tem sido vista como um ato autoritário, um exercício de poder no qual o Estado/profissionais impõe (m) uma diretriz e as mesmas têm que cumprir de um momento para o outro.

Nas entrevistas, um familiar discutia a duração das internaçôes e não entendia por que agora eram tão curtas, quando outrora os pacientes passavam meses dentro 
dos hospitais, o que dava certo alívio às famílias. Se isso não é mais possível, se a assistência extra-hospitalar e a reinserção social são as metas da reforma, as famílias têm apresentado resistências para se engajar nos projetos terapêuticos. Quando a internação era a única alternativa, o peso que representa um indivíduo acometido por uma doença crônica era reduzido, como apontam nossos participantes e a literatura (CAMPOS; SOARES, 2005; SILVA; SADIGURSKY, 2008; CAMATTA; SCHNEIDER, 2009). Assim, "frente ao impacto do adoecimento, as possibilidades de trocas afetivas que, de fato, sejam verdadeiras ficam reduzidas, impondo aos familiares a vivência de sentimentos e emoções que são difíceis de elaborar e entender" (BORBA; SCHWARTZ; KANTORSKI, 2008, p. 589). Portanto, não tem sido um processo muito simples para estas famílias aderir às perspectivas de tratamento preconizadas pelo paradigma psicossocial, fato este que, somado à desassistência que ainda existe, faz com que alguns familiares resistam à implementação das novas propostas de cuidado.

Entendemos, assim, que as dificuldades encontradas por usuários, familiares e equipes de saúde mental são decorrentes, em parte, das mudanças em curso em termos dos modelos assistenciais e do que isso representa em termos de organização dos serviços, da rede de saúde, dos modos de trabalho, gestão e participação da família no cuidado. Produzir um cuidado em saúde mental baseado no acolhimento, no vínculo e na responsabilização requer o enfrentamento dos problemas em relação ao modo de funcionamento dos serviços substitutivos e da rede de saúde de uma forma geral. Sabemos que há uma articulação precária entre os CAPS e a rede de atenção básica, bem como da necessidade de repensar sua função na rede, rever o modelo de funcionamento ambulatorial pregnante e a formação acadêmica dos profissionais, que é insatisfatória para o cuidado de portadores de transtornos mentais. Além disso, as possibilidades de referenciamento são pequenas em função da precariedade da rede de serviços substitutivos na nossa realidade e destes com a rede SUS como um todo. Sabemos, por sua vez, que isso decorre de um desequilíbrio entre os recursos e investimentos da área hospitalar e da atenção básica e da falta de uma rede de atenção não hospitalar e comunitária ampla e efetiva, fruto de um planejamento inadequado de como se tem dado a transição entre os modelos (DESVIAT, 1999; LIMA; SILVA, 2004).

A quantidade de Centros de Atenção Psicossocial do tipo III - onde é possível realizar internação em caso de crise - ainda é pequena, existindo hoje apenas 
122241 serviços em todo o território nacional, sendo que não há nenhum em Natal. A existência de leitos psiquiátricos em hospitais gerais ainda é insignificante, existindo apenas 40 no país. Os Centros de Convivência e Cultura estão restritos a 51, indicando claramente a carência desse dispositivo importante para a circulação dos usuários na rede social, também indisponível na nossa realidade (BRASIL, 2009a). Dificuldades como estas são usadas pelos movimentos antirreforma para questionar a eficácia da atenção à saúde mental extra-hospitalar. A expansão dos CAPS tipo III e a implementação de leitos em hospitais gerais são apontados pelo Ministério da Saúde como os pontos nodais a serem trabalhados neste momento da reforma (BRASIL, 2009b). Assim, o cenário de dificuldades dos serviços substitutivos em atender à demanda crescente, de dar respostas à crise e oferecer suporte às famílias, dificuldades aparentemente resolvidas no modelo manicomial, tem produzido insegurança e descrédito junto a alguns familiares, no que diz respeito ao movimento da reforma psiquiátrica.

Por fim, isso aponta para questôes importantes em termos de organização das práticas profissionais nos serviços substitutivos, no que diz respeito à incorporação das famílias no processo de reinserção social de portadores de transtornos mentais. Essas pessoas apresentam dificuldades em termos de autonomia e integração social, que repercutem no funcionamento familiar. Mudar uma lógica de cuidado em saúde mental que avance no sentido da não exclusão das mesmas não se consegue sem oferecer apoio, assessoramento e capacitação às famílias para lidar com seus membros. A primeira preocupação da equipe é que tais familiares tenham informações claras, atualizadas e consistentes sobre os rumos da política de saúde mental e da realidade dos serviços locais, como funcionam, quais seus objetivos e sua equipe de cuidadores. Sem isso, ficam vulneráveis às informaçôes distorcidas, na maioria dos casos, veiculadas na mídia, acerca da falta de êxito das propostas reformistas.

Em segundo lugar, é preciso ajudar as famílias em termos da estruturação da sua vida cotidiana e convívio com seu familiar, orientá-las em termos de estratégias práticas de manejo da enfermidade, esclarecer sobre as propostas terapêuticas, compartilhar informações sobre diagnóstico, medicação, o que fazer em situação de crise, dentre outros aspectos. Estimular a família acerca da participação nas diversas redes de suporte social e comunitário que possam existir no seu entorno, bem como em associações de familiares e usuários de saúde mental, são açôes 
importantes também. Além disso, é preciso discutir as condições em que se encontra essa família, sejam financeiras, sociais, emocionais, etc, para daí traçar as reais possibilidades de suporte familiar e, consequentemente, que ela possa ser um recurso ativo no processo de cuidado e reinserção social desse usuário.

Sabemos que nem todas as famílias se engajam e se responsabilizam pelo cuidado de seus membros, o que dificulta em muito o processo de trabalho nesse campo, mas a maioria desses familiares está implicada e participa, apenas não se sente preparada para cuidar, tem medo e não recebe nenhum apoio e capacitação dos serviços. É nesse sentido que chamamos atenção para a urgência em incorporar os familiares às propostas terapêuticas e de reabilitação de acordo com o paradigma psicossocial, pois sem eles as possibilidades de êxito ficam reduzidas.

\section{Considerações finais}

Docomplexopanoramaexposto, evidencia-sequeaconstruçãodacorresponsabilidade entre técnicos e familiares, no que toca ao cuidado no campo da saúde mental, deve vir acompanhada de açôes de suporte às famílias, de mudanças nos modos de trabalho e gestão, bem como de avanços em relação às políticas de inclusão social e reabilitação psicossocial, de fortalecimento de mecanismos de controle social, de estímulo ao empoderamento dos usuários e familiares, no sentido de fazer avançar o processo de desinstitucionalização em saúde mental.

\section{Referências}

AFONSO, M. L.; ABADE, F. L. Para reinventar as rodas: rodas de conversa em direitos humanos. Belo Horizonte: RECIMAM, 2008.

AMARANTE, P. (Org.). Loucos pela Vida - a trajetória da reforma psiquiátrica no Brasil. Rio de Janeiro: SDE/ENSP, 1995.

BASAGLIA, F. A instituição negada. São Paulo: Graal, 1991.

BIELEMANN, V. et al. A inserção da família nos centros de atenção psicossocial sob a ótica de seus atores sociais. Texto contexto - Enfermagem. Florianópolis, v. 18, n. 1, p. 131-139, 2009. BORBA, L.O; SCHWARTZ, E.; KANTORSKI, L. P. A sobrecarga da família que convive com a realidade do transtorno mental. Acta Paul. Enferm. São Paulo, v. 21, n. 4, p. 588-594, 2008.

BRASIL. Ministério da Saúde. Saúde Mental em Dados. Brasília, n. 6, ano IV, junho de 2009a. Disponível em: www.saude.gov.br/bvs/saudemental 
BRASIL. Ministério da Saúde. Secretaria de Atenção à Saúde. Departamento de Ações Programáticas Estratégicas. Relatório de Gestão 2008. Desafios para consolidar a mudança no modelo: enfrentar a lacuna assistencial nas grandes cidades, ampliar a rede nas áreas dessassistidas, mudar o paradigma de cuidado em saúde mental na atenção primária. Brasília, 2009b (versão preliminar).

BRASIL. Ministério da Saúde. Secretaria de Atenção à Saúde. Departamento de Ações Programáticas Estratégicas. Saúde mental no SUS: os centros de atenção psicossocial. Brasília, 2004.

CAMATTA, M.W; SCHNEIDER, J.F. O trabalho da equipe de um Centro de Atenção Psicossocial na perspectiva da família. Revista Escola de. Enfermagem. USP. São Paulo, v. 43, n. 2, p. 393-400, 2009.

CAMPOS, P.H.F; SOARES, C.B. Representação da sobrecarga familiar e adesão aos serviços alternativos em saúde mental. Psicologia em Revista. Belo Horizonte, v. 11, n. 18, p. 219-237, dez. 2005.

COLVERO, L. de A.; IDE, C.A.C; ROLIM, M.A. Família e doença mental: a difícil convivência com a diferença. Revista da Escola de Enfermagem USP. São Paulo, v. 38, n. 2, p. 197-205, 2004.

CONSOLI, L.G.; HIRDES, A.; COSTA, J.S. Saúde mental nos municípios do Alto Uruguai, RS, Brasil: um diagnóstico da reforma psiquiátrica. Ciência \& Saúde Coletiva, Rio de Janeiro, v. 14, n. 1, p. 117-128, 2009.

COSTA-ROSA, A. O modo psicossocial: um paradigma das práticas substitutivas ao modo asilar. In: Amarante, P. (Org.). Ensaios: subjetividade, saúde mental, sociedade. Rio de Janeiro: Fiocruz, 2003. p. 141-168.

DESVIAT, M. A reforma psiquiátrica. Rio de Janeiro: Fiocruz, 1999.

DIMENSTEIN, M. et al. A experiência de familiares no cuidado em saúde mental. Arquivos Brasileiros de Psicologia. Rio de Janeiro, v. 59, n. 2, p. 143-155, 2007.

FOUCAULT, M. História da loucura na idade clássica. São Paulo: Perspectiva, 2004.

HIRDES, A. A reforma psiquiátrica no Brasil: uma (re)visão. Ciência \& Saúde Coletiva, Rio de Janeiro, v. 14, n. 1, p. 297-305, 2009.

JORGE, M.S.B. et al. Representações sociais das famílias e dos usuários sobre participação de pessoas com transtorno mental. Revista da Escola de. Enfermagem da USP. São Paulo, v. 42, n. 1, p. 135-142, 2008.

KUHN, T.S. A estrutura das revoluçôes cientificas. São Paulo: Perspectiva, 2006.

LIMA, M. da G.; SILVA, G.B. A reforma psiquiátrica no Distrito Federal. Revista Brasileira de. Enfermagem. Brasília, v. 57, n. 5, p. 591-595, 2004.

MELMAN, J. Família e doença mental. São Paulo: Escritus, 2001. 
NAVARINI, V.; HIRDES, A. A família do portador de transtorno mental: identificando recursos adaptativos. Texto contexto - Enfermagem. Florianópolis, v. 17, n. 4, p. 680-688, 2008. ROMAGNOLI, R.C. Famílias na rede de Saúde Mental: um breve estudo esquizoanalítico. Psicologia em Estudo, Maringá, v. 11, n. 2, p. 305-314, 2006.

ROTELLI, F.; LEONARDIS O. de; MAURI, D. Desinstitucionalização, uma outra via. In: NICÁCIO, F. (Org.): Desinstitucionalização. 2a Ed. São Paulo: Hucitec, 2001. p. 17-59. SARACENO, B. Reabilitação psicossocial: uma estratégia para a passagem do milênio. In: PITTA, A. (Org.). Reabilitação psicossocial no Brasil. São Paulo: Hucitec, 1996. p. 13-18.

SEVERO, A.K.S. A cronificação nos serviços substitutivos na rede de saúde mental de Natal/ $R N$. Dissertação (Mestrado em Psicologia) - Programa de Pós-Graduação em Psicologia, Universidade Federal do Rio Grande do Norte, Natal, 2009.

SILVA, M.B. de C; SADIGURSKY, D. Representaçôes sociais sobre o cuidar do doente mental no domicílio. Revista Brasileira de Enfermagem. Brasília, v. 61, n. 4, p. 428-434, 2008.

WAIDMAN, M.A.P.; ELSEN, I. O cuidado interdisciplinar à família do portador de transtorno mental no paradigma da desinstitucionalização. Texto contexto - Enferm. Florianópolis, v. 14, n. 3, p. 341-349, 2005.

YASUI, S.; COSTA-ROSA, A. A Estratégia Atenção Psicossocial: desafio na prática dos novos dispositivos de Saúde Mental. Saúde em Debate. Rio de Janeiro, v. 32, p. 27-37, 2008.

\section{Notas}

${ }^{1}$ Esta pesquisa contou com o apoio financeiro do CNPq na forma de Bolsa de Produtividade em Pesquisa, Apoio Técnico, Mestrado e Iniciação Científica.

${ }^{2}$ Pesquisa de Iniciação Científica vinculada ao projeto de mestrado "A cronificação nos serviços substitutivos na rede de saúde mental de Natal/RN" (SEVERO, 2009). 


\section{The Psychosocial Care Strategy and family participation in mental health care}

This study aimed to discuss the way that families of individuals with mental health disturbances experience the political changes in the area, what they think about the new participation demands and about the impact that these demands have on their daily relations with the mental health services, and on their family care practices. The study was conducted from November 2008 to February 2009 in a mental health service in the city of Natal, Brazil. It is part of a master's dissertation project that sought to analyze the chronic processes in this service. The results brought into evidence the several difficulties experienced by family members with the new mental health care proposals, that directly interfere in the co-responsibility perspective proposed by the Psychosocial Care Strategy. We believe that in order to promote the mental health deinstitutionalization process, the construction of co-responsibility between technical workers and family members must include: supportive actions to the families; changes in the work and management modes; advances in the social inclusion and psychosocial rehabilitation policies; mechanisms for the strengthening of social control; and empowerment stimulus for the client and his family members.

> Key words: psychiatric reform; mental health; psychosocial rehabilitation, co-responsibility, family. 